\title{
Expression of Intermediate Filaments in the Balbiani Body and Ovarian Follicular Wall of the Japanese Quail (Coturnix japonica)
}

\author{
Daniela Rodler Fred Sinowatz \\ Department of Veterinary Sciences, Institute of Anatomy, Histology and Embryology, University of Munich, \\ Munich, Germany
}

\section{Key Words}

Folliculogenesis · Intermediate filaments • Ovary • Quail

\begin{abstract}
In the present study, we examined the distribution of 6 groups of intermediate filaments (IFs; cytokeratins, CKs, vimentin, synemin, desmin, glial fibrillary acidic protein and lamins) in oocytes and follicular walls of the Japanese quail (Coturnix japonica) during their development using immunohistochemical and ultrastructural techniques. A distinctly vimentin- and synemin-positive Balbiani body, which is a transient accumulation of organelles (mitochondria, Golgi complex and endoplasmic reticulum) that occurs in the oocytes of all vertebrates including birds, could be detected in the oocytes of primordial and early pre-vitellogenic follicles. In larger pre-vitellogenic follicles, the Balbiani body has dispersed and the positivity of the granulosa cells appeared to concentrate in the basal portion of their cytoplasm. Our ultrastructural data demonstrated that the matrix of the Balbiani body consists of fine IFs, which may play a role in the formation and dispersion of the Balbiani body. Of the CKs studied (panCK, CK5, CK7, CK8, CK14, CK15, CK18 and CK19), only CK5 showed a slight positive staining in both the theca externa and the Balbiani bodies of pre-vitellogenic oocytes. In conclusion, our data, which describe the changes in avian IF protein expression during folliculogenesis, suggest that
\end{abstract}

the functions of the IFs (vimentin and synemin) of oocytes and follicular walls are not primarily mechanical but may be involved in the transient tethering of mitochondria in the area of the Balbiani body and in the gain of endocrine competence during the differentiation of granulosa cells.

Copyright $\odot 2013$ S. Karger AG, Basel

\section{Introduction}

The quail ovary contains thousands of follicles of various sizes and provides a unique model for the study of follicular development. The follicles of birds can be classified into primordial, pre-vitellogenic and vitellogenic follicles. Follicles become vitellogenic once the deposition of yolk platelets begins in the central ooplasm. Furthermore, it has been shown that the maturation of chicken follicles proceeds in 3 phases [Schneider, 1995].

\begin{tabular}{ll} 
Abbreviations used in this paper \\
\hline CK & cytokeratin \\
GFAP & glial fibrillary acidic protein \\
IFs & $\begin{array}{l}\text { intermediate filaments } \\
\text { panCK }\end{array}$ \\
pancytokeratin
\end{tabular}


Initially, numerous primary oocytes increase in size from $60 \mu \mathrm{m}$ to $2-3 \mathrm{~mm}$ in diameter over several months, although they still lack the typical 'yellow' yolk [Schjeide et al., 1970]. Second, several of these oocytes enter a slow growth phase. Third, upon reaching a size of 6-7 mm, approximately $75 \%$ of all oocytes (at least in chicken) either are destined for resorption or enter the last phase in which the huge polylecithal ovum (approximately $8 \mathrm{~cm}$ in diameter in chicken or $2 \mathrm{~cm}$ in quail) is finally ovulated. The final maturation phase is characterised by a dramatic growth spurt over several days during which the oocyte extracts enormous amounts of lipids and other yolk components from the circulatory system for future deposition inside the ooplasm.

The process of oocyte growth in the avian ovary is tightly associated with the functional differentiation of the granulosa and thecal layers of the maturing follicles [Johnson and Woods, 2009]. Additionally, there are alterations in the typically avian intra-ooplasmic, yolky Balbiani body (formerly called the 'yolk nucleus') of previtellogenic follicles until their material disperses to the outer periphery of the oocyte during later follicular development [Guraya, 1976]. The Balbiani body lies adjacent to the nuclear membrane and has a spherical shape of varying densities. This structure is transiently present in the oocytes of all vertebrates, including birds, and mainly consists of a large aggregate of multiform mitochondria, dictyosomes of the Golgi apparatus, endoplasmic reticulum and lipid droplets. In quail, it also contains chromophilic chromatoid bodies. The role of the Balbiani body, which has been demonstrated in all classes of vertebrates [Guraya, 1979], remains unclear. It has been suggested that it may play a role in the multiplication of mitochondria or in the production of yolk [Guraya, 1979; Kloc et al., 2004, 2012]. It has generally been thought that the primary role of the Balbiani body is to provide precursor yolk material and other metabolic requirements for the oocyte [Guraya, 1976]. It has also been hypothesised that the Balbiani body plays a role in the selection of the healthiest mitochondria for the future zygote [Cox and Spradling, 2003] and that it is a component of a vegetal pole RNA transport pathway [Kloc et al., 2008].

The cytoskeletal properties of the cells in the differentiating follicular wall (granulosa cells and theca cell layers) of birds are not known in any detail. Previous studies have primarily focused on the events related to the regulation of steroidogenesis during the differentiation of granulosa cells from pre-ovulatory follicles [Johnson et al., 2004] and on its function in the mechanical support of the huge polylecithal ovum [Van Nassauw et al., 1992].
In mammalian follicles, a network of specialised cytoskeletal components has been described, which consists of intermediate filaments (IFs) [Wendl et al., 2012], microtubules and actin microfilaments; however, in birds, the cytoskeletal machinery that generates this structural organisation supporting the giant avian oocyte has not been extensively investigated.

IFs are ubiquitous elements of the vertebrate cell cytoskeleton with an average diameter of $10 \mathrm{~nm}$; they include cytokeratins (CKs), vimentin, desmin, glial fibrillary acidic protein (GFAP), neurofilament proteins (all of these reside in the cytoplasm) and lamins (within the nucleus). IFs constitute a large protein family of over 60 members that exhibit cell-specific expression patterns, and they are the most stable components of the cytoskeleton in the cells under physiological conditions. They have long half-lives, which are roughly equivalent to the cell generation time, whereas the half-lives of their corresponding mRNAs are short [Coleman and Lazarides, 1992]. Therefore, it was assumed for a long time that the main role of IFs was to maintain a fixed cellular architecture that protects cells against mechanical stress.

The expression of several classes of cytoplasmic IFs in the ovary has been described for several mammalian and avian species [Czernobilsky et al., 1985; Gall, 1991; Santini et al., 1993; Gallicano et al., 1994; Bukovsky et al., 1995; Ricken et al., 1995; van den Hurk et al., 1995; Pan and Auersperg, 1998; Löffler et al., 2000; Marettová and Maretta, 2002]. In some of these studies, vimentin and CKs were detected within the granulosa cells of follicles at various stages of growth and atresia, in luteal cells of the corpus luteum throughout the luteal phase, and in oocytes from both fetal and adult ovaries [Czernobilsky et al., 1985; Gall, 1991; Santini et al., 1993; Gallicano et al., 1994; van den Hurk et al., 1995; Marettová and Maretta, 2002]. Of vertebrate germ cells, nuclear IFs, called lamins, have thus far only been found in the oocytes of $\mathrm{Xe}$ nopus [Gall et al., 1989] and in the oocytes of mice [Arnault et al., 2010]. IF proteins were also detected in simple animals, such as the sweet water sponge Hydra and the nematode Caenorhabditis [Herrmann et al., 2009]. However, in contrast to microfilaments and microtubules, IFs are not expressed in plants and fungi. They are likely to be absent because the body plans of plants and fungi depend on external mechanical support, which is provided by cell walls [Hermann et al., 2009]. Similarly, insects do not possess cytoplasmic IF proteins.

Recently, it has become apparent that IFs are highly dynamic and modified by phosphorylation, glycosylation and transglutamination [Omary et al., 2006; Hyder et al., 
2008]. Several new studies suggest that, in addition to providing mechanical stability and being part of desmosomes, the IF network is also involved in many important physiological functions such as organelle transport, signal transduction, cell polarity and gene regulation [Pallari and Eriksson, 2006; Kim et al., 2007; Kim and Coulombe, 2007; Hyder et al., 2008; Iwatsuki and Suda, 2010].

Giles et al. [2006] have investigated IF occurrence in healthy and tumorous ovarian surface epithelium cells of domestic hens. In their study, no CKs have been found in the granulosa cells of the hen's ovary, but a distinct vimentin staining was observed. In our previous work [Rodler and Sinowatz, 2011], we could not identify any CKs in the granulosa cells of the Japanese quail (Coturnix japonica) either. Furthermore, Giles et al. [2006] included a figure in their paper in which a circumscribed vimentin-positive area near the nucleus can be observed in oocytes. The authors did not comment on this finding, but we assume that this vimentin-positive area corresponds to the Balbiani body.

In the present communication, the aims of our study were to verify the circumstantial finding of Giles et al. [2006] and to find out whether a vimentin-positive Balbiani body could also be found in a different avian species such as the quail. We present data to more accurately observe the participation and role of the IFs in oocytes and cells of the follicular wall of quail ovaries. Therefore, we have characterised IFs using immunohistochemistry and transmission electron microscopy to suggest a possible role of IFs in the morphological changes of the oocyte and the follicular wall during folliculogenesis in this bird species.

\section{Materials and Methods}

\section{Animals and Tissue Preparation}

Healthy $(\mathrm{n}=25), 6$-month-old female Japanese quails (C. japonica) that were regularly egg laying were used in this study. The birds were provided by the Department of Veterinary Sciences, Institute of Veterinary Nutrition, University of Munich, Germany. All of the birds were housed as indoor breeders and were fed a commercial diet and water ad libitum. Because no experimental procedures were involved in this study, the German Law on Animal Welfare $(\$ \$ 8 b, 9.2)$ and the Animal Care Committee of the Veterinary Faculty of the University of Munich authorised the sacrifice of these Japanese quails for scientific purposes.

Experiments were performed according to institutional guidelines. Under $\mathrm{CO}_{2}$ anaesthesia, the quails were decapitated, and their ovaries were removed and fixed in Bouin's solution $(1,500$ $\mathrm{ml}$ of picric acid, $500 \mathrm{ml}$ of glacial acetic acid and $100 \mathrm{ml}$ of $37 \%$ formalin) for $14 \mathrm{~h}$. The tissue was collected $8 \mathrm{~h}$ before ovulation. Appropriate tissue samples of different follicle sizes were cut from the ovary and dehydrated in a graded series of ethanol before be- ing embedded using an automatic tissue processor (Shandon $\mathrm{Du}-$ plex Processor, Frankfurt, Germany) and a Histostat tissue embedding center (Reichert-Jung, Vienna, Austria). Paraplast sections of $5 \mu \mathrm{m}$ were cut with a rotary microtome (Microm HM 340E; Leitz, Wetzlar, Germany), and the sections were collected on 'Superfrost' glass slides (Carl Roth, Karlsruhe, Germany).

In the present study, we used the following classification of follicle sizes as proposed by Sasanami et al. [2004]: primordial follicles $(40-65 \mu \mathrm{m})$, pre-vitellogenic follicles $(65-450 \mu \mathrm{m})$ and vitellogenic follicles, which are divided into small white follicles ( $\leq 1 \mathrm{~mm})$, small yellow follicles (1-2 mm), F5 follicles (2-4 mm), F4 follicles (4-8 mm), F3 follicles (8-12 mm), F2 follicles (12-15 $\mathrm{mm})$ and $\mathrm{F} 1$ follicles $(\geq 15 \mathrm{~mm})$. The follicle diameters that were used in our study have been measured with ImageJ software (Java, open source, Bethesda, Md., USA). One section of the entire ovary was shot to provide a macroscopic overview picture, and $1 \mathrm{sec}-$ tion of a block was conventionally stained with haematoxylineosin to provide a histological overview.

\section{Immunohistochemistry}

Paraffin sections were dewaxed and then washed 3 times for 5 min with phosphate-buffered saline at $\mathrm{pH}$ 7.4. For some primary antibodies, pre-treatment was necessary. The primary antibodies, secondary antibodies and the pre-treatment procedures that were used in this study are listed in table 1. Endogenous peroxidase activity was blocked with $7.5 \% \mathrm{H}_{2} \mathrm{O}_{2}$ at room temperature for $10 \mathrm{~min}$. Non-specific antibody binding was blocked with Dako protein block serum free (Dako Deutschland GmbH, Hamburg, Germany) for $10 \mathrm{~min}$. The sections were incubated with the primary antibody at $6^{\circ} \mathrm{C}$ overnight. Localisation of the antigen was achieved using the avidin-biotin complex technique [Hsu et al., 1981]. The appropriate biotinylated secondary antibodies were incubated with the sections for $16 \mathrm{~h}$ at room temperature.

Subsequently, treatment with StreptABComplex/HRP (Dako Deutschland $\mathrm{GmbH}$ ) was performed for $30 \mathrm{~min}$ at room temper-

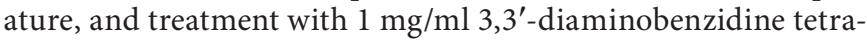
hydrochloride (DAB tablets, $10 \mathrm{mg}$; BIOTREND Chemikalien $\mathrm{GmbH}, \mathrm{Köln}$, Germany) was performed for $5 \mathrm{~min}$. All of the incubations were performed in a humidified chamber. Sections were left unstained or counterstained in haematoxylin (20 s), dehydrated and mounted with Eukitt quick-hardening mounting medium for microscopy (Fluka Analytical ${ }^{\odot}$; Sigma-Aldrich Laborchemikalien GmbH, Seelze, Germany).

Negative controls were performed by either replacing the primary antibody with buffer or non-immune serum or by incubating with the 3,3'-diaminobenzidine reagent alone to exclude the possibility of detecting non-suppressed endogenous peroxidase activity. A lack of detectable staining in the negative controls demonstrated that the reactions were specific. The images were captured with a Leica Labo-Lux ${ }^{\circledR}$ microscope equipped with a Zeiss Axiocam ${ }^{\circledR}$ camera (Zeiss, Munich, Germany). As positive controls, ovarian tissue from several mammalian species (cow, cat and $\operatorname{dog}$ ) of proven immunoreactivity was used.

\section{Immunohistochemistry of Frozen Sections}

Samples of the ovaries of 3 quails were shock frozen in liquid nitrogen. Cryosections $(10 \mu \mathrm{m})$ were cut using a Kryostat HM 500 OM (Microm, Walldorf, Germany). The temperature of the microscope stage was kept at $-15^{\circ} \mathrm{C}$. The sections were placed on 'Superfrost Plus' glass slides (Carl Roth, Karlsruhe, Germany) and 
Table 1. Antibodies used for immunohistochemistry

\begin{tabular}{|c|c|c|c|c|}
\hline Antigen & Primary antibody & Secondary antibody & Dilution & Pre-treatment \\
\hline PanCK & $\begin{array}{l}\text { Anti-panCK, mouse, monoclonal } \\
\text { (Biocarta, Hamburg, Germany) }\end{array}$ & $\begin{array}{l}\text { Biotinylated anti-mouse IgG, rabbit; } \\
\text { 1:300 (Dako) }\end{array}$ & $1: 100$ & Trypsin (Sigma-Aldrich) for $20 \mathrm{~min}$ \\
\hline CK5 & $\begin{array}{l}\text { Anti-keratin K5, guinea pig, polyclonal } \\
\text { (Progen Biotechnik, Heidelberg, Germany) }\end{array}$ & $\begin{array}{l}\text { Biotinylated anti-guinea pig IgG, goat, } \\
\text { 1:300 (Vector, Burlingame, Calif., USA) }\end{array}$ & $1: 50$ & - \\
\hline CK7 & $\begin{array}{l}\text { Anti-CK7, mouse, monoclonal } \\
\text { (BioGenex, Hamburg, Germany) }\end{array}$ & $\begin{array}{l}\text { Biotinylated anti-mouse IgG, rabbit, } \\
\text { 1:300 (Dako) }\end{array}$ & $1: 400$ & Pepsin (Dako) for $15 \mathrm{~min}$ \\
\hline CK8 & $\begin{array}{l}\text { Anti-CK8, mouse, clone C-51, monoclonal } \\
\text { (Novus Biologicals, Cambridge, UK) }\end{array}$ & $\begin{array}{l}\text { Biotinylated anti-mouse IgG, rabbit, } \\
\text { 1:300 (Dako) }\end{array}$ & $1: 500$ & $\begin{array}{l}0.1 \% \text { proteinase (bacterial type XXIV; } \\
\text { Sigma-Aldrich) for } 10 \mathrm{~min}\end{array}$ \\
\hline CK14 & $\begin{array}{l}\text { Anti-keratin K14, guinea pig, polyclonal } \\
\text { (Progen Biotechnik, Heidelberg, Germany) }\end{array}$ & $\begin{array}{l}\text { Biotinylated anti-guinea pig IgG, goat, } \\
\text { 1:300 (Vector) }\end{array}$ & $1: 100$ & - \\
\hline CK15 & $\begin{array}{l}\text { Anti-vimentin, mouse, clone Vim 3B4, } \\
\text { monoclonal (Dako) }\end{array}$ & $\begin{array}{l}\text { Biotinylated anti-mouse IgG, rabbit, } \\
\text { 1:300 (Dako) }\end{array}$ & $1: 100$ & $\begin{array}{l}\text { Citrate buffer ( } \mathrm{pH} 6.0 \text {; Dako) heated } \\
\text { in a microwave oven followed by a } \\
\text { pre-treatment of } 20 \mathrm{~min}\end{array}$ \\
\hline $\begin{array}{l}\text { CK18 and } \\
\text { CK19 }\end{array}$ & $\begin{array}{l}\text { Anti-keratin K18 (19), guinea pig, } \\
\text { polyclonal (Progen Biotechnik) }\end{array}$ & $\begin{array}{l}\text { Biotinylated anti-guinea pig IgG, goat, } \\
\text { 1:300 (Vector) }\end{array}$ & $1: 200$ & - \\
\hline Vimentin & $\begin{array}{l}\text { Anti-vimentin, mouse, clone Vim 3B4, } \\
\text { monoclonal (Dako) }\end{array}$ & $\begin{array}{l}\text { Biotinylated anti-mouse IgG, rabbit, } \\
\text { 1:300 (Dako) }\end{array}$ & $1: 500$ & $\begin{array}{l}0.1 \% \text { proteinase (bacterial type XXIV; } \\
\text { Sigma-Aldrich) for } 10 \mathrm{~min}\end{array}$ \\
\hline Synemin & $\begin{array}{l}\text { Anti-synemin, rabbit, monoclonal Sigma } \\
\text { S9075 (Sigma-Aldrich, Oberkochen, Germany) }\end{array}$ & $\begin{array}{l}\text { Biotinylated anti-rabbit IgG, pig, 1:300 } \\
\text { (Dako) }\end{array}$ & $1: 250$ & $\begin{array}{l}\text { Citrate buffer (pH } 6.0 \text {; Dako) heated } \\
\text { in a microwave oven followed by a } \\
\text { pre-treatment of } 20 \mathrm{~min}\end{array}$ \\
\hline Desmin & $\begin{array}{l}\text { Anti-desmin, mouse, clone DE-U-10, } \\
\text { monoclonal (GeneTex Inc., Eching, Germany) }\end{array}$ & $\begin{array}{l}\text { Biotinylated anti-mouse IgG, rabbit, } \\
\text { 1:300 (Dako) }\end{array}$ & $1: 200$ & - \\
\hline Lamin A & $\begin{array}{l}\text { Anti-lamin A, mouse, 133A2, monoclonal } \\
\text { (Santa Cruz Biotechnology, Heidelberg, } \\
\text { Germany) }\end{array}$ & $\begin{array}{l}\text { Biotinylated anti-mouse IgG, rabbit, } \\
\text { 1:300 (Dako) }\end{array}$ & $1: 750$ & $\begin{array}{l}\text { Citrate buffer ( } \mathrm{pH} 6.0 \text {; Dako) heated } \\
\text { in a microwave oven followed by a } \\
\text { pre-treatment of } 20 \mathrm{~min}\end{array}$ \\
\hline Lamin B1 & $\begin{array}{l}\text { Anti-lamin B1, mouse, (119D5-F1), } \\
\text { monoclonal (Santa Cruz Biotechnology) }\end{array}$ & $\begin{array}{l}\text { Anti-mouse IgG biotinylated, rabbit, } \\
\text { 1:300 (Dako) }\end{array}$ & $1: 750$ & $\begin{array}{l}\text { Citrate buffer ( } \mathrm{pH} 6.0 \text { ) heated in a } \\
\text { microwave oven for } 20 \text { min (Dako) }\end{array}$ \\
\hline GFAP & $\begin{array}{l}\text { Anti-GFAP, mouse, monoclonal } \\
\text { (BioGenex) }\end{array}$ & $\begin{array}{l}\text { Anti-mouse IgG biotinylated, rabbit, } \\
\text { 1:300 (Dako) }\end{array}$ & $1: 400$ & - \\
\hline
\end{tabular}
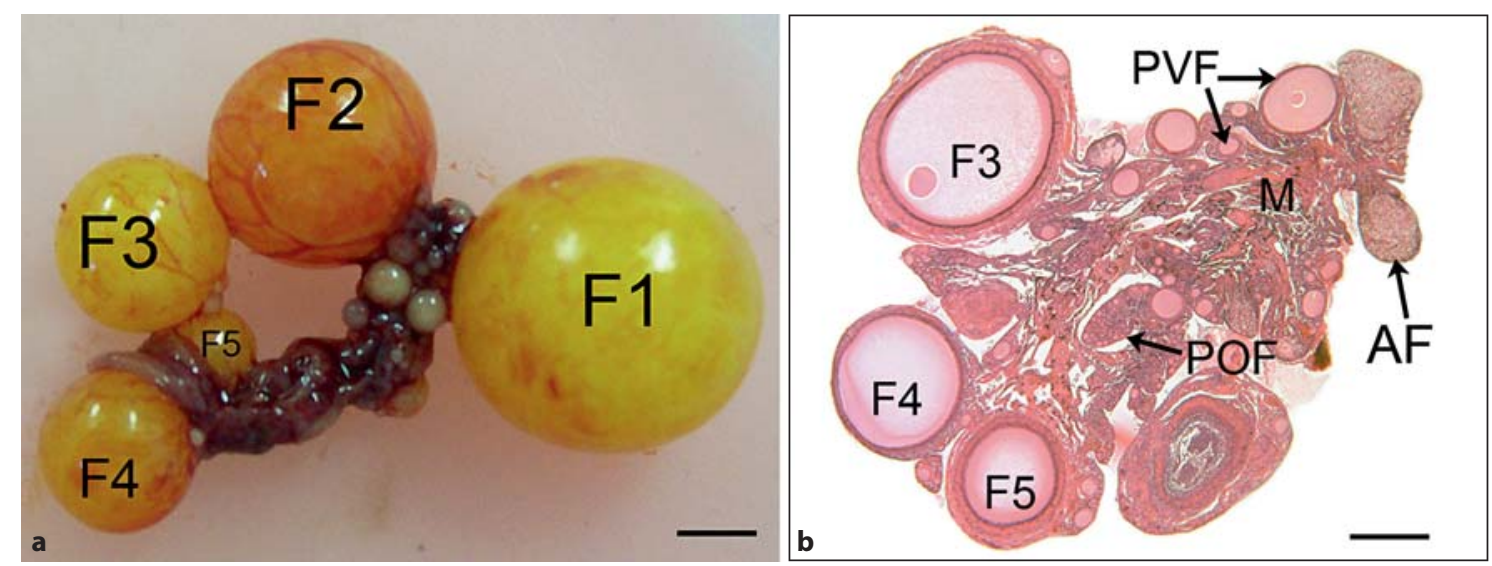

Fig. 1. Macroscopic overview of the grape bunch-shaped quail ovary (a) showing different follicular stages (F5F1) of white and yellow yolk content and microscopic view (b) with additionally marked cortex-localised primordial follicles (POF), pre-vitellogenic follicles (PVF), atretic follicles (AF) and the ovarian medulla (M). Scale bars $=5 \mathrm{~mm}$. 
dried for $1 \mathrm{~h}$ at room temperature. Then, the sections were fixed in $100 \%$ acetone (at $4^{\circ} \mathrm{C}$ ) for $2 \mathrm{~min}$ and stored at $-20^{\circ} \mathrm{C}$ until used for the immunohistochemical investigations.

The immunohistochemical staining was performed with an identical protocol [Hsu et al., 1981] as for paraffin sections, but microwave pre-treatment was omitted. Primary antibodies against panCK, CK5 and vimentin (table 1) were used in identical concentrations as mentioned for the paraffin sections.

\section{Transmission Electron Microscopy}

Small pieces (side lengths of $1 \mathrm{~mm}$ ) of quail ovary were removed from the different locations within the ovary and fixed by immersion in Karnovsky's solution (2.5\% glutaraldehyde and 2\% paraformaldehyde) at $4^{\circ} \mathrm{C}$ for $24 \mathrm{~h}$.

Afterwards, the sections were treated with $1 \%$ osmium tetroxide (Plano, Wetzlar, Germany)/1.5\% potassium ferrocyanide (Sigma-Aldrich, Steinheim, Germany), dehydrated in a graded series of ethanol solutions (50, 70 and 90\%, and absolute ethanol for 30 min each) and embedded in Polyembed 812 BDMA (Polysciences, Eppelheim, Germany). Semi-thin sections of $1 \mu \mathrm{m}$ were cut and stained with Richardson's solution [Richardson et al., 1960].

Ultra-thin sections were cut using a diamond knife (ReichertLabtec, Wolfratshausen, Germany), placed on 150-mesh copper grids (Polysciences), stained with uranyl acetate (Scientific LTD., Stansted, UK) and lead citrate (Agar Aids, Stansted, UK), and examined under a transmission electron microscope (EM 902; Zeiss, Oberkochen, Germany).

\section{Results}

\section{Overview and Organisation of the Quail Ovary}

The ovary of the quail is composed of the cortex, medulla and ovarian stalk. The prominent, healthy atretic follicles of the laying quail lend the characteristic grapeshaped appearance to the avian ovary. At various sizes and stages of development, these follicles are mainly located inside the cortex (fig. la, b), whereas the medulla and ovarian stalk contain large nerve bundles and blood vessels. Deep surface crypts partially divide the ovarian cortical region into compartments. Primordial, pre-vitellogenic and vitellogenic follicles with white and yellow yolk content can be distinguished.

Primordial follicles are distributed in the peripheral area of the cortex, usually directly beneath the ovarian surface epithelium. The size of primordial follicles ranges between 40 and $65 \mu \mathrm{m}$. They consist of a primary oocyte enclosed by flat or cuboidal follicle cells, the granulosa cells. In the outer periphery, beyond the granulosa cells, a layer of fibroblasts with interspersed melanocytes surrounds the primordial follicles. The ooplasm of the oocyte shows the conspicuous avian feature, the Balbiani body, which consists of an accumulation of organelles and can be found adjacent to the nuclear membrane. The location and organisation of the Balbiani body during follicular development can be studied via the schema in figure $2 \mathrm{a}-\mathrm{f}$.

Early pre-vitellogenic follicles, which have diameters from 65 to $450 \mu \mathrm{m}$, are also situated near the ovarian surface epithelium and are often found at the surface of the organ. Late pre-vitellogenic follicles $(450-800 \mu \mathrm{m}$ in diameter) are in the deeper regions of the cortex.

Vitellogenic and pre-ovulatory follicles, which roughly range from 1 to $15 \mathrm{~mm}$ and have incorporated a large amount of yolk by their mature stages, are surrounded by a single mono-layer of flat to cuboidal granulosa cells that sit upon a distinct laminin-positive basement membrane. Inner and outer thecal layers that are composed of fibroblasts and smooth muscle cells surround these follicles.

\section{Immunohistochemistry}

The differences in the quality of the immunostaining (with all of the antibodies used in this study) of the relevant ovarian structures are listed in table 2.

Of all of the CKs studied (panCK, CK5, CK7, CK8, CK14, CK15, CK18 and CK19), only CK5 showed slight positive staining in the Balbiani body of pre-vitellogenic oocytes (fig. 3a). PanCK and CK5 showed positive staining in the theca externa (fig. 3b). None of the anti-CK antibodies used displayed positive immunostaining in the developing granulosa of the follicles (which, however, is frequently observed in mammals) at any stage of their development. Additionally, $10-\mu \mathrm{m}$-thick frozen sections immunostained with antibodies against panCK and CK5 labelled neither the granulosa cells nor the Balbiani body of the oocytes. A distinct staining was only observed in the surface epithelium of the ovary.

Interesting changes in the distribution of the IFs vimentin and synemin could be observed in oocytes and granulosa cells during folliculogenesis, and these changes showed a similar and characteristic pattern. The strongest staining with respect to the granulosa cells and Balbiani bodies was observed in healthy primordial and early pre-vitellogenic follicles (fig. 3c, g, h). Distinct vimentin- (fig. 3c) and synemin-positive (fig. 3g) Balbiani bodies were detected in the oocytes of these follicles. In larger pre-vitellogenic follicles, immunostaining appeared to concentrate in the basal cytoplasmic area of the granulosa cells (fig. 3d).

During the later stages of folliculogenesis, vimentin and synemin staining appeared to be significantly reduced and the vimentin in the cytoplasm of the granulosa cells of vitellogenic follicles was barely detectable. Similar to vimentin and the somewhat weaker synemin reactions at oocytes in the vitellogenic stages, a clearly positive area 


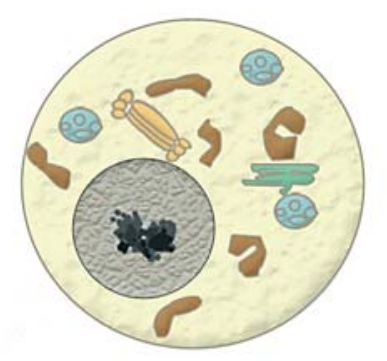

a

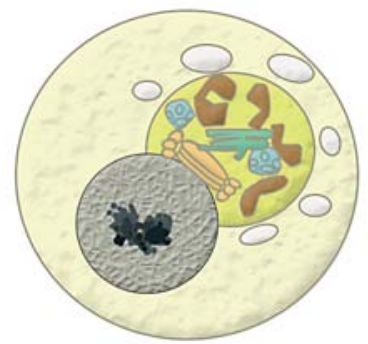

b
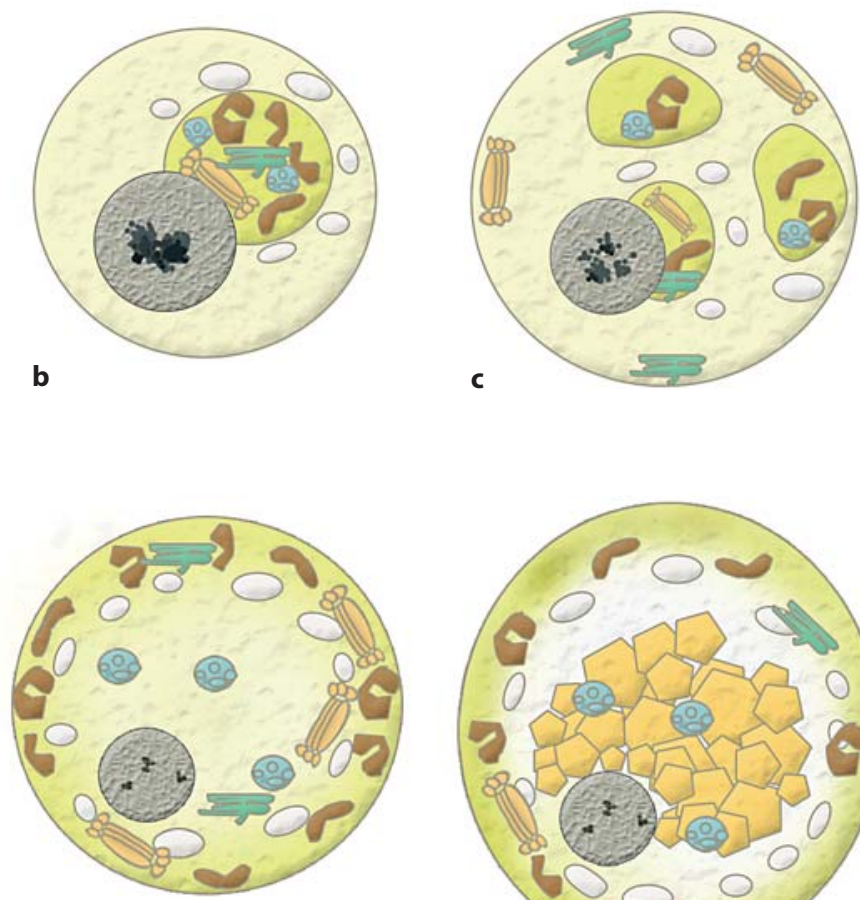

e

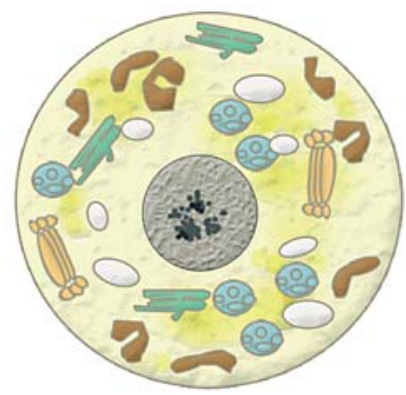

d

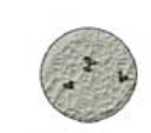

Nucleus

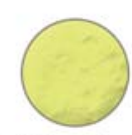

Balbiani body
Fig. 2. Scheme showing the development of the Balbiani body during folliculogenesis according to Guraya [1976] and Carlson et al. [1996]. a Primordial follicles without Balbiani body. b Early previtellogenic follicles with developing yolky Balbiani body adjacent to the nuclear membrane, mainly containing mitochondria, Golgi structures, multivesicular bodies, smooth endoplasmic reticulum and lipid droplets arranged in the periphery. c Later stages of previtellogenic follicles with dispersed Balbiani body; its organelles are located beneath the periphery of the oocyte. $\mathbf{d}$ Further developed follicles with dissolved Balbiani body showing peripheral mitochondria and organelles distributed throughout the ooplasm. e Later pre-vitellogenic stages with mitochondria, Golgi structures and lipid droplets distributed in the periphery of the oocyte. $\mathbf{f ~ V i -}$ tellogenic stages with organelles arranged in the periphery, central accumulation of yolk platelets and Balbiani body 'residues' (secondary aggregation). RER = Rough endoplasmic reticulum. could only be detected at the outer ooplasm subjacent to the oocyte membrane (fig. 3i, j). Although distinct immunostaining for vimentin and synemin was observed in stroma cells, particularly those surrounding the interstitial glands, positive staining was only observed in the theca interna and theca externa in the vitellogenic follicles. The immunoreactions for vimentin and synemin in the granulosa and theca of degenerating follicles were generally stronger than in healthy follicles (fig. 3e).

In the non-hyalinised form of atresia, several vimentin- and synemin-positive cells that can be regarded as granulosa and theca cells have invaded the ooplasm of the degenerating oocyte (fig. 3f). Other ovarian tissues that showed a distinct and strong staining for vimentin and synemin were the surface epithelium, the endothelia of the blood vessels, the epithelial cells of the rete ovarii and the perineurium of the nerves.

The desmin staining pattern appeared dot like and/or spindle shaped. Desmin could not be detected in the walls of either immature or atretic follicles. It was only found as circumscribed spots and spindle-shaped features in detached parts of the theca interna of mature follicles 
Table 2. Immunostaining of the follicular wall and other ovarian structures

\begin{tabular}{|c|c|c|c|c|c|c|c|c|c|c|c|c|c|c|c|}
\hline \multirow[t]{2}{*}{ Antibody } & \multicolumn{3}{|c|}{ Primordial follicle } & \multicolumn{3}{|c|}{ Pre-vitellogenic follicle } & \multicolumn{4}{|c|}{ Vitellogenic follicle } & \multicolumn{5}{|c|}{ Other ovarian tissue } \\
\hline & GC & OOP & $\mathrm{BB}$ & $\mathrm{TH}$ & GC & OOP & $\mathrm{TE}$ & TI & GC & OOP & ST & $\mathrm{V}$ & $\mathrm{Nv}$ & OSE & TA \\
\hline PanCK & - & - & - & $-1+$ & - & - & + & - & - & - & - & - & - & $++^{1}$ & \\
\hline CK5 & - & - & $-1+$ & - & - & - & + & - & - & - & - & - & - & ++ & - \\
\hline CK7 & - & - & - & - & - & - & - & - & - & - & - & - & - & $-1+$ & - \\
\hline $\mathrm{CK} 8$ & - & - & - & - & - & - & - & - & - & - & - & - & - & - & \\
\hline CK14 & - & - & - & - & - & - & - & - & - & - & - & - & - & ++ & - \\
\hline CK15 & - & - & - & - & - & - & - & - & - & - & - & - & - & - & \\
\hline CK18 & - & - & - & - & - & - & - & - & - & - & - & - & - & + & - \\
\hline CK19 & - & - & - & - & - & - & - & - & - & - & - & - & - & $-1+$ & - \\
\hline Vimentin & +++ & $-/+$ & ++ & + & ++ & - & + & + & $++^{2}$ & - & + & ++ & ++ & ++ & - \\
\hline Synemin & + & - & + & $-1+$ & $-1+$ & - & $-1+$ & $-1+$ & - & - & $-1+$ & + & + & + & - \\
\hline Desmin & - & - & - & - & - & - & $-1+{ }^{3}$ & $+{ }^{4}$ & - & - & + & + & - & - & $-1+$ \\
\hline Lamin A & - & - & - & - & - & - & - & - & $-/+^{5}$ & - & - & - & - & - & - \\
\hline Lamin B1 & - & - & - & - & - & - & - & - & $-/+^{5}$ & - & - & - & - & - & - \\
\hline GFAP & - & - & - & - & - & - & - & - & - & - & - & - & - & - & - \\
\hline
\end{tabular}

- = Negative; $-/+=$ weak; $+=$ moderate; $++=$ strong; +++ = very strong; $\mathrm{BB}=$ Balbiani body; $\mathrm{GC}=$ granulosa cells; $\mathrm{Nv}=$ nerve; $\mathrm{OOP}=$ ooplasm; OSE = ovarian surface epithelium; $\mathrm{ST}=$ ovarian stroma cells; $\mathrm{TA}=$ tunica albuginea; $\mathrm{TE}=$ theca $\mathrm{ex}-$ terna; $\mathrm{TH}=$ theca around pre-vitellogenic follicles; $\mathrm{TI}=$ theca interna; $\mathrm{V}=$ vessel.

${ }^{1}$ In contrast to bovines, where the granulosa cells show positive staining with many CK antibodies, only the surface epithelium seems to contain CKs in quail, whereas the granulosa cells have not yet shown positive staining with CK antibodies.
2 The positive reaction seems to concentrate at the basal side of the granulosa cells with the growing follicle.

${ }^{3}$ The theca externa of vitellogenic follicles is positive, but for the most part, the positive dot-like staining does not surround the whole follicle.

${ }^{4}$ The staining displays only a few scattered dots.

${ }^{5}$ This weak staining is regarded as non-specific because it is located in the cytoplasm instead of the nucleus. (fig. 3k, l), in the tunica albuginea, in the tunica media of vessels and in the smooth muscle-like cell bundles that were distributed throughout the ovarian stroma.

No specific staining for lamin A or B1 could be observed in the nuclei of primordial/pre-vitellogenic/vitellogenic oocytes with the antibodies that were used in this study. Permeabilisation (in citrate buffer) with a microwave oven did not improve immunostaining. A distinct immunostaining was found in the granulosa cells of the antral follicles; however, it was confined to the cytoplasm of the cells (and not, as expected, to the lamina of the nuclei) and was therefore considered non-specific.

No positive immunostaining was obtained with the GFAP antibodies in either the oocyte or in the cell layers of the follicular wall.

\section{Ultrastructure}

In the early pre-vitellogenic follicles, a concentric, aggregated organelle mass, which was the Balbiani body, could be detected adjacent to the nuclear membrane (fig. 4a). It mainly consisted of Golgi structures, pleomorphic mitochondria, smooth endoplasmic reticulum, multivesicular bodies, lipid droplets and electron-dense bodies. Between these Balbiani body organelles, dark, filamentous structures could be detected with higher magnification (fig. 4b). These structures were assumed to be IFs (vimentin).

In late pre-vitellogenic follicles, filamentous structures in the outer ooplasm could be observed, which lay subjacent to the oocyte membrane and were often extended by granulosa cell processes (fig. 4c). Dislocation of mitochondria into the periphery of the oocyte could also be observed subjacent to the filamentous structures during this follicular stage. Higher magnifications of these filamentous structures showed that they have diameters of approximately $10 \mathrm{~nm}$. This small band of filaments separates the ooplasm into an inner and outer zone (fig. 4d). The latter zone is most likely involved in granulosa cell-oocyte interactions. 


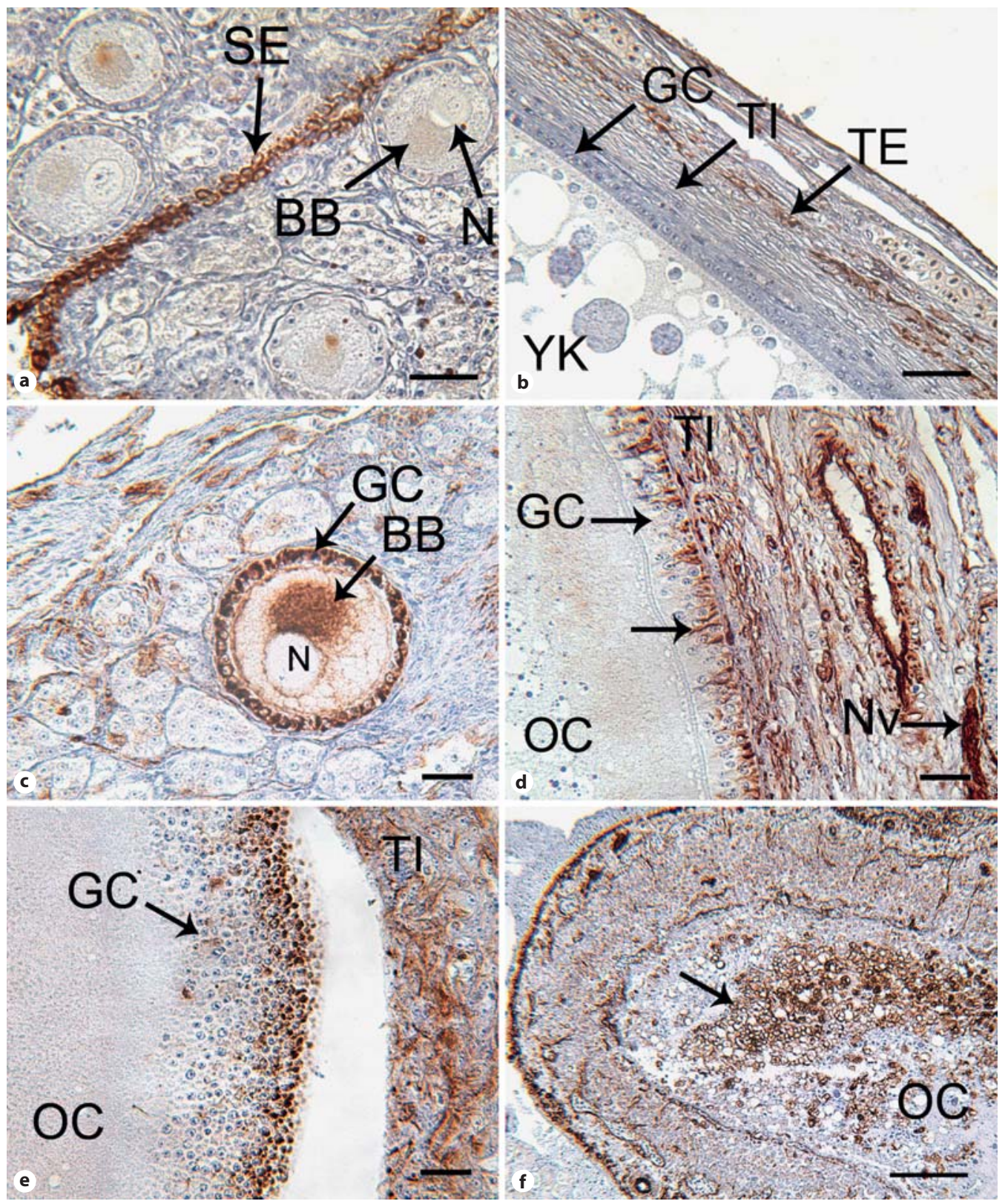

Fig. 3. a Immunostaining of the ovarian surface epithelium (SE) with CK5 antibodies. This reaction is very strong within the surface epithelium. The granulosa cells around the oocytes of early pre-vitellogenic follicles show neither staining with panCK antibodies nor with other CKs; this trend continues throughout all follicular stages. Only their Balbiani bodies (BB) adjacent to their nuclei $(\mathrm{N})$ show weak positive staining. Scale bar $=40 \mu \mathrm{m}$. b Immunostaining of a vitellogenic follicle with CK5 antibodies. Distinct positive reactions can be noticed at the theca externa (TE), whereas the theca interna (TI) and the granulosa cells (GC) remain unstained. Scale bar $=120 \mu \mathrm{m}$. c Immunostaining of an early pre-vitellogenic follicle with vimentin antibodies. The follicle shows a strong reaction within the cytoplasm of its granulosa cell layer (GC). In addition, its Balbiani body (BB) shows positive staining. $\mathrm{N}=$ Nucleus. Scale bar $=35 \mu \mathrm{m}$. $\mathbf{d}$ Immunostaining of a late pre-vitellogenic follicle with vimentin antibodies. Vimentin (arrow) is still present in the granulosa cells (GC) but appears now to be concentrated in the basal area of the cytoplasm. The surrounding theca layers, especially the theca interna (TI), also show strong positive reactions, especially in nerves $(\mathrm{Nv})$ and fibroblasts. OC = Oocyte. Scale bar $=20 \mu \mathrm{m}$. e Immunostaining of an atretic pre-vitellogenic follicle with vimentin antibodies. The positive vimentin signal becomes stronger in the atretic follicles. The typically multi-layered granulosa cells (GC) caused by atresia separate from the theca interna (TI). Positive reactions can be observed in their basal cells and in both theca layers. OC = Oocyte. Scale bar $=50 \mu \mathrm{m}$. $\mathbf{f}$ Immunostaining of an atretic pre-vitellogenic follicle with vimentin antibodies. At advanced stages of atresia, vimentin-positive cells (arrow) of the follicular wall invade the degenerating oocyte (OC). Scale bar $=100 \mu \mathrm{m}$. 


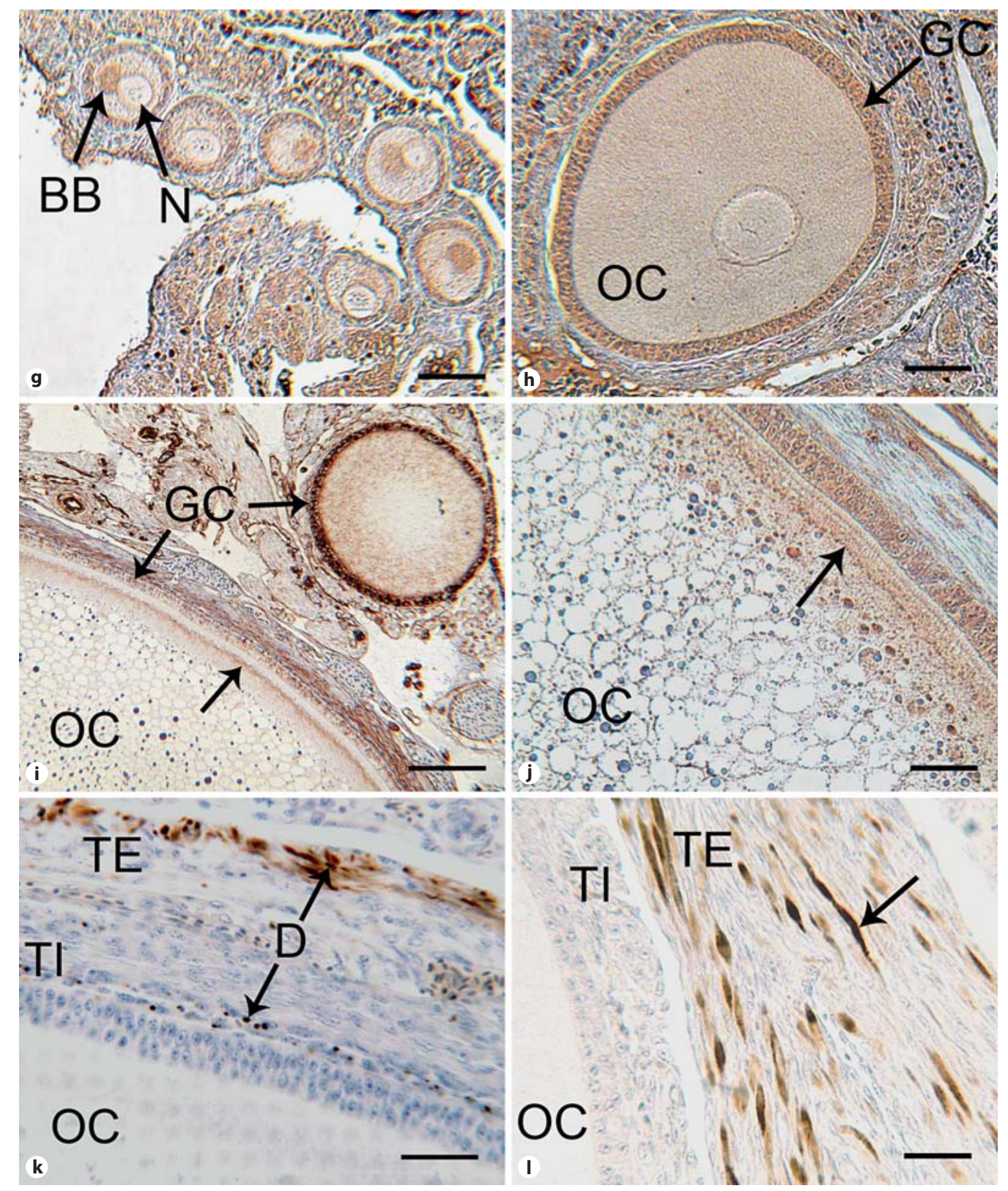

Fig. 3. g Immunostaining of early pre-vitellogenic follicles with synemin antibodies. Moderate staining of the granulosa layer and a distinct positive staining in the Balbiani body (BB) adjacent to the nucleus $(\mathrm{N})$ is noticed. Scale bar $=60 \mu \mathrm{m}$. $\mathbf{h}$ Immunostaining of a late pre-vitellogenic follicle with synemin antibodies. Because the Balbiani body has dispersed, only a weak reaction with antisynemin can be observed inside the ooplasm of the oocyte (OC). The granulosa cells (GC) clearly show positive reaction. Scale bar $=35 \mu \mathrm{m}$. i, $\mathbf{j}$ Immunostaining of a pre-vitellogenic and vitellogenic follicle with vimentin antibodies (i) and of a vitellogenic follicle with synemin antibodies (j). By comparing the vitellogenic oocytes (OC; $\mathbf{i}, \mathbf{j}$ ), similar observations (but somewhat weaker with synemin) can be made on a clearly positive area (arrow) at the outer ooplasm subjacent the oocyte membrane. Note also the decrease in the vimentin reactions in the granulosa cells (GC) of the vitellogenic follicle compared to the pre-vitellogenic follicle (i). Although weaker, this decrease is also detected with synemin. Scale bars $=50$ (i) and $40 \mu \mathrm{m}(\mathbf{j})$. $\mathbf{k}$ Immunostaining of a pre-vitellogenic follicle with desmin antibodies (D). In this follicle (and larger stages), desmin can clearly be detected in the theca externa (TE) and in some parts of the theca interna (TI). OC = Oocyte. Scale bar $=30 \mu \mathrm{m}$. I Immunostaining of a pre-vitellogenic follicle with desmin antibodies. The staining pattern results due to the agglomeration of bundles of desmin filaments within the cytoplasm of smooth muscle cells. Scale bar $=20 \mu \mathrm{m}$. 
Fig. 4. a Ultrastructual view of an early pre-vitellogenic follicle. The Balbiani body (BB) adjacent to the nuclear (N) membrane inside the oocyte (OC) can be identified. Various lipid droplets (arrows) and large amounts of mitochondria (thin arrow) surround the Balbiani body and Golgi stacks (thick arrow). The granulosa cells (GC) of this follicular stage are flat. Scale bar $=2 \mu \mathrm{m}$. $\mathbf{b}$ Higher magnification of the Balbiani body (BB). Filamentous structures, regarded as IFs (arrow), are distributed between the cell organelles (e.g. mitochondria and yolk granules) of the Balbiani body. Scale bar $=0.25 \mu \mathrm{m}$. c Ultrastructural view of a pre-vitellogenic follicle. Clearly aggregated filamentous structures (FI) can be identified at the outer periphery of the ooplasm in the oocyte (OC). GC = Granulosa cell; $\mathrm{N}=$ nucleus. Scale bar $=2.5 \mu \mathrm{m}$. d Higher magnification: according to Callebaut [1991], these filaments (FI) separate the ooplasm into an exooplasm (ExOp), which may serve as a granulosa-oocyte transit compartment and an endooplasm (EndOp). GC = Granulosa cell; $\mathrm{OC}=$ oocyte. Scale bar $=0.5$ $\mu \mathrm{m}$.
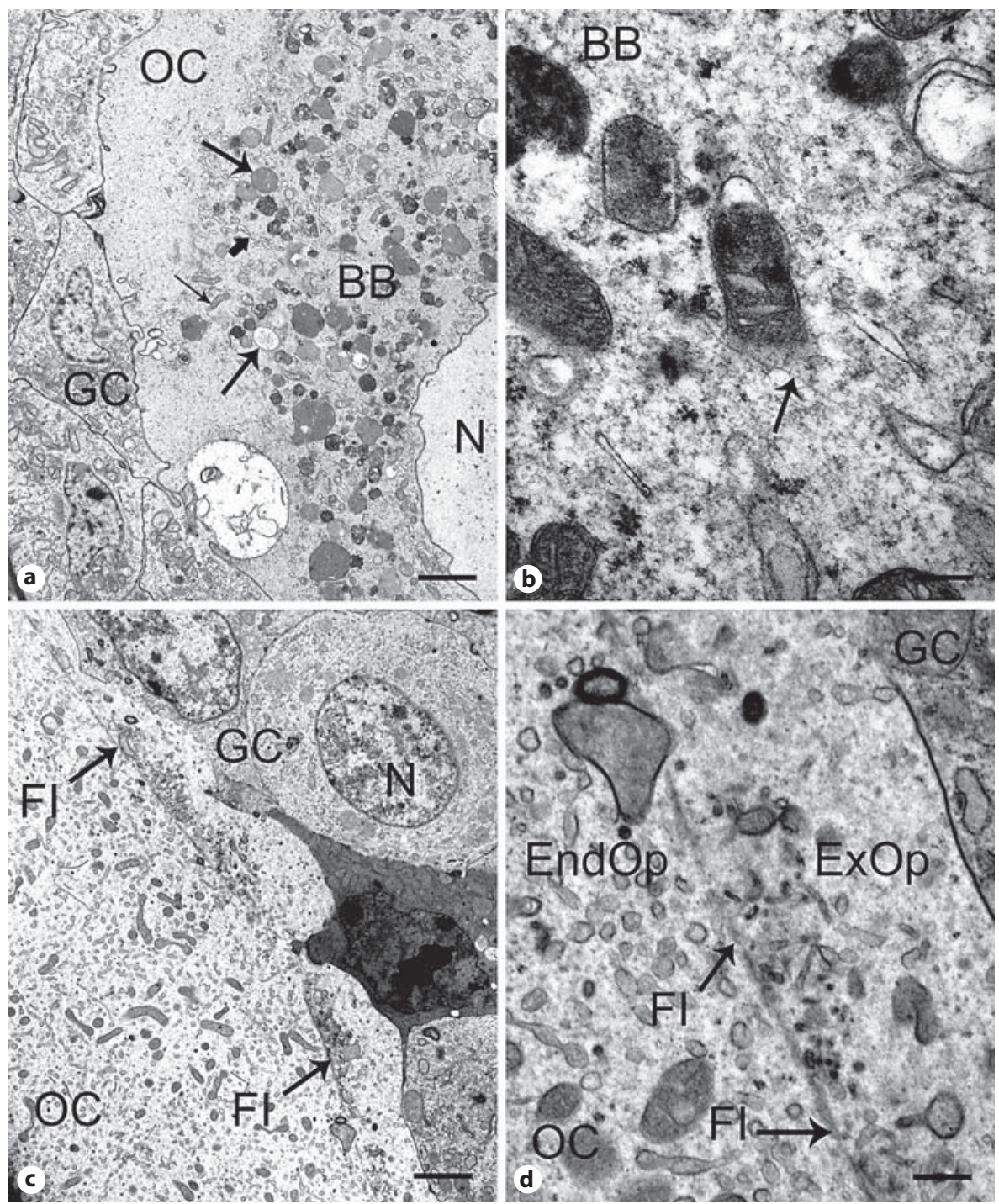

\section{Discussion}

The present study reports on the changes that the IFs of the oocytes and the follicular wall (granulosa and thecal cells) undergo during folliculogenesis in the quail (C. japonica).

Molecular and ultrastructural studies clearly demonstrated that, at least in the Xenopus, the Balbiani body is involved in the transport of organelles, such as mitochondria and germinal granules, but also of RNA to the vegetal cortex of the oocyte [Kloc et al., 2002; Kloc and Etkin, 2005]. Comparison of the ultrastructure and intracellular behaviour during oocyte development and molecular composition of the Balbiani body showed that the Balbiani body of birds and Xenopus are homologous struc- tures. We suggest that the Balbiani body of quail oocytes is also responsible for the accumulation, sorting and maturation of macromolecules, particularly mRNAs and organelles such as mitochondria, that are involved in the specification of a germ line.

An interesting finding of our immunohistochemical studies was the co-localisation of vimentin and synemin in a circumscribed area of pre-vitellogenic oocytes during a restricted period of oocyte development. Our additional ultrastructural studies suggest that this area corresponds to the Balbiani body. Synemin is a cytoskeletal protein that was originally identified as an IF-associated protein. Subsequent studies have shown that synemin is an unusually large member of the IF superfamily [Bellin et al., 1999]. Molecular interaction studies demonstrated 
that purified synemin interacts with desmin, vimentin and $\alpha$-actinin. Transfection studies indicate that synemin requires the presence of another IF, such as vimentin, to assemble into an IF [Minin and Moldaver, 2008]. The transient co-localisation of synemin and vimentin within the area of the Balbiani body of quail oocytes supports this idea.

The Balbiani body area was also weakly positive for CK5. Because CKs are not likely to be present in the Balbiani body, and considering the negative results of the frozen sections, we believe this weak CK5 positivity to be a non-specific reaction.

In older investigations of human [Czernobilsky et al., 1985] and other mammalian ovaries [van den Hurk et al., 1995], co-expression of vimentin and CK filaments was demonstrated at the granulosa layer. In the rat, as the follicular epithelium becomes multi-layered during follicular growth, keratin was retained by granulosa cells adjacent to the follicular basement membranes but disappeared from cells that were displaced towards follicle centres. From day 7 of postnatal development, large follicles lacked keratin altogether [Pan and Auersperg, 1998]. The authors hypothesised that the loss of keratin from all granulosa cells suggests that the required stromal signal for its expression ceased as the perifollicular stroma differentiates into the theca.

However, the cytoskeleton of granulosa cells has been thoroughly studied in only a few avian species, although the analysis of its cytoskeletal architecture would lead to a better understanding of the marked changes in the shape of granulosa cells during folliculogenesis. We demonstrate that no CKs could be found in the cytoplasm of granulosa cells at any follicular stage, whereas they were distinctly positive for vimentin, which confirms our previous findings in the quail [Rodler and Sinowatz, 2011]. As for vimentin, marked immunostaining in granulosa cells has previously been demonstrated for several avian species, such as the chicken (Gallus domesticus) [Giles et al., 2006] and the emu (Dromaius novaehollandiae) [Madekurozwa, 2007] and in several mammals, including humans [Czernobilsky et al., 1985]. As for CKs, in the mouse, CK8, which is regarded as characteristic of epithelial cells, is distinctly expressed in granulosa cells of primordial and transitory follicles, but none of the other traditional epithelial markers, such as E-cadherin, were detected [Mora et al., 2012]. From the primary oocyte stage onward, CK8 immunostaining decreased until its expression was no longer detectable. In the human adult ovary, CK8 expression also decreased during follicular maturation in vivo [Löffler et al., 2000], whereas in the rat, no CK immunostaining was found in the follicular epithelium at any stage of folliculogenesis [Mora et al., 2012]. These results imply that data obtained on the IF composition of granulosa cells in one species cannot be extrapolated to another [Mora et al., 2012]. The lack of CK protein expression in the granulosa cells of the quail, which was found in our study, adds further support to the hypothesis that the granulosa cell layer of the quail, and presumably other avian species, is not a classic epithelium. However, regarding previous studies and considering that we only used adult ovaries, it cannot be ruled out that CKs may be expressed in quail follicles of embryonic or early postnatal ovaries.

Ultrastructurally, we could demonstrate that the space between the organelles in the Balbiani body was filled with numerous IFs. We assume that the components of the Balbiani body observed by electron microscopy (numerous mitochondria, stacks of Golgi apparatuses and numerous cisternae of the endoplasmic reticulum) are temporarily trapped in a dense network of vimentin filaments. When the oocytes increase in size, the Balbiani body disappears and the mitochondria become more equally distributed within the (outer) cytoplasm of the germ cell. The immunohistochemically vimentin-positive filaments appear to be located at the periphery of the oocyte and finally completely vanish with the accumulation of yolk. Our data suggest that vimentin, which is only expressed during a certain period of quail oocyte development (in pre-vitellogenic oocytes of sizes between 65 and $450 \mu \mathrm{m}$ ) and at special locations (mainly in the Balbiani body and later in the periphery of the oocyte), is of minor importance for the mechanical stability of the cell. It may be involved in the formation of the Balbiani body and could therefore play a role in the RNA transport pathways of the oocyte. In accordance with immunohistochemical observations, the dense filaments that were detected in the periphery of the pre-vitellogenic follicles by electron microscopy could also be interpreted as vimentin filaments; however, because they 'disappeared' in the vitellogenic follicles, it is more likely that they can be interpreted as F-actin filaments.

Recent studies demonstrated that interactions with vimentin filaments affect the motility, distribution and anchorage of mitochondria within the cytoplasm [Minin and Moldaver, 2008]. In cells lacking vimentin filaments, the normal distribution of mitochondria within the cytoplasm becomes disrupted, and the intracellular motility of mitochondria appears increased relative to control cells that express a normal vimentin network. We assume that the accumulation of mitochondria and other cell or- 
ganelles in the region of the Balbiani body may be caused by the temporarily increased expression of vimentin in this cytoplasmic region. Later in oocyte development, when vimentin expression is reduced, mitochondria regain their motility and are more evenly displaced within the cytoplasm. In support of this idea, it has been shown that mitochondria are delivered and tethered to such areas of the cell in which metabolic requirements are temporarily high, such as the Balbiani body of the growing oocyte of vertebrates [Chada and Hollenbeck, 2003].

The oocytes of certain insects also contain peculiar organelles, similar to the Balbiani body of vertebrates, termed accessory nuclei [Bilinski and Kloc, 2002]. Immunohistochemical studies and in situ hybridisation have shown that these cellular structures contain p-coilin, sm-proteins and small nuclear RNAs. During perivitellogenesis, the accessory nuclei migrate to the cortical ooplasm of the oocyte in which they reside until the onset of embryogenesis. Bilinsky and Kloc [2002] suggested that the accessory nuclei are vehicles for the transport and localization of small nuclear RNAs to the periphery of the oocytes.

During oogenesis, germ plasm forms distinct cellular structures, such as the pole plasm in Drosophila or the Balbiani body, an aggregate of mitochondria and other organelles, which are also found in birds and mammals. Whereas in birds and most other vertebrates the mechanisms regulating germ plasm assembly are largely unknown, recent studies in zebrafish [Bontems et al., 2009] have unveiled some important steps of this process. These studies demonstrate that the gene buc (bucky ball) controls the formation of the Balbiani bodies in this species. Because buc homologues have been described in many vertebrate genomes, including birds and mammals, buc can be considered the first gene necessary and sufficient for germ plasm organisation in vertebrates [Bontems et al., 2009].

In contrast, the mechanical support of the cellular architecture of the huge avian oocyte is maintained by the inner perivitelline layer [Kinoshita et al., 2010; Rodler, 2011; Rodler et al., 2012], which is a tough extracellular network and the avian equivalent to the zona pellucida. It forms during folliculogenesis and appears to be responsible for the stabilisation of the oocyte by acting as an 'exoskeleton'.

The decrease in the vimentin amount in the cytoskeleton of granulosa cells (infranuclear aspects of granulosa cells in larger follicles) correlates with the beginning of their endocrine functions. The steroidogenic competence of the granulosa cells is gained during the transition of the follicles from 6-8 to 9-12 $\mathrm{mm}$ in the hen and from 2 to $4 \mathrm{~mm}$ in the quail, possibly under the stimulatory regulation of FSH [Tilly et al., 1991].

In other endocrine organs, such as the adrenal gland [Shen et al., 2012], the contribution of the cytoskeleton to steroidogenesis has been demonstrated previously. Before steroid synthesis starts in the adrenal gland, cholesterol esters must be de-esterified and transported to the mitochondria. Both cholesterol-containing droplets and mitochondria are known to be attached to IFs. Vimenin filaments appear to act by keeping lipid droplets and mitochondria apart [Hall and Almahbobi, 1997]. Disruption of the vimentin network accompanied by contractile processes could allow these structures to come together. This would afford the transfer of cholesterol to the steroidogenic pathway [Hall and Almahbobi, 1997] in healthy steroidogenic cells. The increased expression of vimentin, which could be detected in atretic follicles of the quail, and which has previously been described in atretic follicles of several mammalian species, is difficult to interpret and needs further investigations.

Desmin could not be detected in the walls of either immature or atretic follicles and was only found as circumscribed bundles of desmin filaments in the theca interna of detached parts of mature follicles. This finding is different from the situation in mammals in which the theca interna usually lacks positivity for desmin. We assume that the theca interna of the mature follicles of the quail is able to actively contract and contribute to the ovulation of the huge oocyte.

In conclusion, our data describing the changes in IF protein expression during folliculogenesis in the quail suggest that IFs of the oocyte and follicular wall do not primarily have mechanical function. Instead, they are most likely involved in the movement of organelles during the formation and dispersion of the ooplasmic Balbiani body, and the granulosa cells during their gain of endocrine competence when they differentiate during follicle selection.

\section{Acknowledgements}

The authors would like to thank the Institute of Veterinary Nutrition, University of Munich, Germany, for providing indoor breeding Japanese quails. The skilful technical assistance by Gabi Russmeier, Monica Settles, Wiebke Scholz and Yilmaz Gök is greatly appreciated. 


\section{References}

Arnault, E., M. Doussau, A. Pesty, B. Lefèvre, Guraya, S.S. (1976) Correlative cytological and A.M. Courtot (2010) Review: lamin A/C, caspase-6, and chromatin configuration during meiosis resumption in the mouse oocyte. Reprod Sci 17: 102-115.

Bellin, R.M., S.W. Sernett, B. Becker, W. Ip, T.W. Huiatt, R.M. Robson (1999) Molecular characteristics and interactions of the intermediate filament protein synemin. Interactions with alpha-actinin may anchor synemincontaining heterofilaments. J Biol Chem 247: 29493-29999.

Bilinski, S.M., M. Kloc (2002) Accessory nuclei revisited: the translocation of snRNPs from the germinal vesicle to the periphery of the future embryo. Chromosoma 111: 62-68.

Bontems, F., A. Stein, F. Marlow, J. Lyautey, T. Gupta, M.C. Mullis, R. Dosch (2009) Bucky ball organizes germ plasm assembly in zebrafish. Curr Biol 19: 414-422.

-Bukovsky, I., R. Halperin, D. Schneider, A. Golan, I. Hertzianu, A. Herman (1995) Ovarian function following abdominal hysterectomy with and without unilateral oophorectomy. Eur J Obstet Gynecol Reprod Biol 58: 29-32.

Callebaut, M. (1991) Light- and electron-microscopic observations on the relationship between prelampbrush oocytes and surrounding granulosa cells in the laying Japanese quail (Coturnix coturnix japonica). Reprod Nutr Dev 31: 461-471.

Carlson, J.L., M.R. Bakst, M.A. Ottinger (1996) Developmental stages of primary oocytes in turkeys. Poult Sci 75: 1569-1578.

Chada, S.R., P.J. Hollenbeck (2003) Mitochondrial movement and positioning in axons: the role of growth factor signaling. J Exp Biol 206: 1985-1992.

Coleman, T.R., E. Lazarides (1992) Continuous growth of vimentin filaments in mouse fibroblasts. J Cell Sci 103: 689-698.

-Cox, R.T., A.C. Spradling (2003) A Balbiani body and the fusome mediate mitochondrial inheritance during Drosophila oogenesis. Development 130: 1579-1590.

Czernobilsky, B., R. Moll, R. Levy, W.W. Franke (1985) Co-expression of cytokeratin and vimentin filaments in mesothelial, granulosa and rete ovarii cells of the human ovary. Eur J Cell Biol 37: 175-190.

Gall, L. (1991) Intermediate filaments in oocytes. Bull Assoc Anat (Nancy) 75: 63-65.

Gall, L., P. Le Guen, D. Huneau (1989) Cytokeratin-like proteins in the sheep oocyte. Cell Differ Dev 28: 95-104.

Gallicano, G.I., C.A. Larabell, R.W. McGaughey, D.G. Capco (1994) Novel cytoskeletal elements in mammalian eggs are composed of a unique arrangement of intermediate filaments. Mech Dev 45: 211-226.

- Giles, J.R., L.M. Olsen, P.A. Johnson (2006) Characterization of ovarian surface epithelial cells from the hen: a unique model for ovarian cancer. Exp Biol Med 231: 17181725. histochemical studies on the avian oogenesis. Z Mikrosk Anat Forsch 90: 91-150.

Guraya, S.S. (1979) Recent advances in the morphology, cytochemistry, and function of Balbiani's vitelline body in animal oocytes. Int Rev Cytol 59: 249-321

Hall, P.F., G. Almahbobi (1997) Roles of microfilaments and intermediate filaments in adrenal steroidogenesis. Microsc Res Tech 36: 463-479.

-Herrmann, H., S.V. Strelkov, P. Burkhard, U. Aebi (2009) Intermediate filaments: primary determinants of cell architecture and plasticity. J Clin Invest 119: 1772-1783.

Hsu, S.M., L. Raine, H. Fanger (1981) The use of antiavidin antibody and avidin-biotin-peroxidase complex in immunoperoxidase technics. Am J Clin Pathol 75: 816-821.

Hyder, C.L., H.M. Pallari, V. Kochin, J.E. Eriksson (2008) Providing cellular signposts post-translational modifications of intermediate filaments. FEBS Lett 582: 2140-2148.

Iwatsuki, H., M. Suda (2010) Seven kinds of intermediate filament networks in the cytoplasm of polarized cells: structure and function. Acta Histochem Cytochem 43: 19-31.

Johnson, A.L., J.T. Bridgham, D.C. Woods (2004) Cellular mechanisms and modulation of activin A- and transforming growth factor beta-mediated differentiation in cultured hen granulosa cells. Biol Reprod 71: 1844-1851.

Johnson, A.L., D.C. Woods (2009) Dynamics of avian ovarian follicle development: cellular mechanisms of granulosa cell differentiation (review). Gen Comp Endocrinol 163: 12-17.

Kim, S., P.A. Coulombe (2007) Intermediate filament scaffolds fulfill mechanical, organizational, and signaling functions in the cytoplasm. Genes Dev 21: 1581-1597.

Kim, S., J. Kellner, C.H. Lee, P.A. Coulombe (2007) Interaction between the keratin cytoskeleton and eEF1Bgamma affects protein synthesis in epithelial cells. Nat Struct Mol Biol 14: 982-983.

Kinoshita, M., D. Rodler, K. Sugiura, K. Matsushima, N. Kansaku, K. Tahara, A. Tsukada, H. Ono, T. Yoshimura, N. Yoshizaki, R. Tanaka, T. Kohsaka, T. Sasanami (2010) Zona pellucida protein ZP2 is expressed in the oocyte of Japanese quail (Coturnix japonica). Reproduction 139: 359-371. biani body and germ cell determinants: 150 years later. Curr Top Dev Biol 59: 1-36.

Kloc, M., L.D. Etkin (2005) RNA localization mechanisms in oocytes. J Cell Sci 118: 269282.

Kloc, M., R.M. Ghobrial, E. Borsuk, J.Z. Kubiak (2012) Polarity and asymmetry during mouse oogenesis and oocyte maturation. Results Probl Cell Differ 55: 23-44.
Kloc, M., S. Bilinski, L.D. Etkin (2004) The Bal-
Kloc, M., M. Jaglarz, M. Dougherty, M.D. Stewart, L. Nel-Themaat, S. Bilinski (2008) Mouse early oocytes are transiently polar: three-dimensional and ultrastructural analysis. Exp Cell Res 314: 3245-3254.

Kloc M., R. Zearfoss, L.D., Etkin (2002) Mechanisms of subcellular mRNA localization. Cell 108: 533-544.

Löffler, S., L.C. Horn, W. Weber, K. SpanelBorowski (2000) The transient disappearance of cytokeratin in humen fetal and adult ovaries. Anat Embryol 201: 201-212.

Madekurozwa, M.C. (2007) An immunohistochemical study of the distribution of intermediate filaments in the ovary of the emu (Dromaius novaehollandiae). Anat Histol Embryol 36: 336-342.

-Marettová, E., M. Maretta (2002) Demonstration of intermediate filaments in sheep ovary. Acta Histochem 104: 431-434.

Minin, A.A., M.V. Moldaver (2008) Intermediate vimentin filaments and their role in intracellular organelle distribution. Biochemistry (Mosc) 73: 1453-1466.

Mora, J.M., M.A. Fenwick, L. Castle, M. Baithun, T.A. Ryder, M. Mobberley, R.S. Franks, K. Hardy (2012) Characterization and significance of adhesion and junction-related proteins in mouse ovarian follicles. Biol Reprod 153: $1-14$

Omary, M.B., N.O. Ku, G.Z. Tao, D.M. Toivola J. Liao (2006) 'Heads and tails' of intermediate filament phosphorylation: multiple sites and functional insights. Trends Biochem Sci 31: 383-394.

Pallari, H.M., J.E. Eriksson (2006) Intermediate filaments as signaling platforms. Sci STKE 366: pe53.

Pan, J., N. Auersperg (1998) Spatiotemporal changes in cytokeratin expression in the neonatal rat ovary. Biochem Cell Biol 76: 2735.

Richardson, K.C., L. Jarett, E.H. Finke (1960) Embedding in epoxy resins for ultrathin sectioning in electron microscopy. Stain Technol 35: 313-323.

Ricken, A.M., K. Spanel-Borowski, M. Saxer, P.R. Huber (1995) Cytokeratin expression in bovine corpora lutea. Histochem Cell Biol 103: 345-354.

Rodler, D. (2011) Histochemical detection of glycoconjugates in the inner perivitelline layer of Japanese quail (Coturnix japonica). Anat Histol Embryol 40: 441-449.

Rodler, D., T. Sasanami, F. Sinowatz (2012) Assembly of the inner perivitelline layer, a homologue of the mammalian zona pellucida. An immunohistochemical and ultrastructural study. Cells Tissues Organs 195: 330339.

Rodler, D., F. Sinowatz (2011) Immunohistochemical and ultrastructural characterization of the ovarian surface epithelium of Japanese quail (Coturnix japonica). Anim Sci J 82: 307-313. 
Santini, D., C. Ceccarelli, G. Mazzoleni, G. Pasquinelli, V.M. Jasonni, G.N. Martinelli (1993) Demonstration of cytokeratin intermediate filaments in oocytes of the developing and adult human ovary. Histochemistry 99: 311-319.

Sasanami, T., M. Ohtsuki, A.M. Hanafy, M. Mori (2004) Accumulation of ZP1 and ZPC in quail perivitelline membrane during follicular development. J Poult Sci 41: 289-297.

-Schjeide, O.A., F. Galey, E.A. Grellert, R. I-San Lin, J. De Vellis, J.F. Mead (1970) Macromolecules in oocyte maturation (review). Biol Reprod 2: 14-43.
Schneider, W.J. (1995) Yolk precursor transport in the laying hen (review). Curr Opin Lipidol 6: 92-96.

Shen, W.J., S.K. Zaidi, S. Patel, Y. Cortez, M. Ueno, R. Azhar, S. Aszhar, F.B. Kraemer (2012) Ablation of vimentin results in defective steroidogenesis. Endocrinology 153: 3249-3257.

Tilly, J.L., K.I. Kowalski, A.L. Johnson (1991) Stage of ovarian follicular development associated with the initiation of steroidogenic competence in avian granulosa cells. Biol Reprod 44: 305-314. van den Hurk, R., G. Dijkstra, F.N. van Mil, S.C. Hulshof, T.S. van den Ingh (1995) Distribution of the intermediate filament proteins vimentin, keratin, and desmin in the bovine ovary. Mol Reprod Dev 41: 459-467.

Van Nassauw, L., F. Harrison, M. Callebaut (1992) Immunolocalization of smooth muscle-like cells in the quail ovary. Eur J Morphol 30: 275-288.

Wendl, J., K. Ebach K, D. Rodler, R.A. Kenngott (2012) Immunocytochemical localization of cytoplasmic and nuclear intermediate filaments in the bovine ovary during folliculogenesis. Anat Histol Embryol 41: 190-201. 